\title{
Ataque fatal en humano, por puma (Puma concolor)
}

\section{Human fatal attack by cougar (Puma concolor)}

\section{Resumen}

El ataque de félidos salvajes a humanos es infrecuente ya que éstos no reconocen a los seres humanos como víctimas.

Estos animales persiguen una gran variedad de presas, desde ungulados, como las cabras y caballos hasta roedores.

Presentamos el caso de una mujer, pastora de rebaño caprino, quien fue atacada por un puma en la zona de la pre-Puna Salteña. La víctima falleció por una hemorragia aguda, secundaria a la sección completa de la vena yugular izquierda producida por las garras del felino.

Palabras clave: Ataque a humanos. Ataque por grandes felinos. Lesiones. Ataque por puma.

\section{Abstract}

Attack of wild felines to humans is rare, since these do not recognize human beings as victims.

These animals are pursuing a wide variety of prey, from ungulates such as goats and horses to rodents.

We present a case of a woman, goat herd herder, who was attacked by a cougar in the area of the pre-Puna Salta. The victim died, for acute hemorrhage secondary to complete section of the left jugular vein caused by the claws of the cat.

Key words: Human attack. Big cat attack. Injury. Cougar attack.

\section{Introducción}

Los ataques por félidos salvajes a humanos son poco frecuentes. Cuando se producen, son dramáticos y fatales ${ }^{1-3}$.

Estos animales consumen principalmente mamíferos medianos y grandes tales como cérvidos y grandes roedores; y en las zonas de pastoreo tienen gran afición por la carne de caballo y ovejas ${ }^{3,4}$.

La provincia de Salta se caracteriza por una gran diversidad fitogeográfica y se distinguen tres regiones principales, Región Chaqueña, Región de los Valles y
Región de Puna y pre-Puna, cada una de ellas caracterizadas por una complejidad orográfica y de suelos, con una gran biodiversidad de especies de carnívoros ${ }^{5}$.

En la región de la Puna se encuentran depredadores tales como el puma, (Puma concolor), el zorro colorado (Pseudalopex culpaeus) y el gato andino (Oreailurus jacobita $)^{4}$.

EI $P$. concolor es uno de los félidos más adaptables, se encuentra en muchos climas desde boreales a tropicales; desde desiertos a bosques húmedos y desde tierras bajas a montañas, desde Alaska hasta el Sur de Argentina y Chile ${ }^{4}$.

\section{Portelli ${ }^{1}$ \\ CR. Eveling ${ }^{2}$ \\ J. Lamas ${ }^{3}$ \\ PJ. Mamaní ${ }^{3}$}

${ }^{1}$ Médica Patóloga. Servicio de Anatomía Patológica. Ministerio Público de Salta.

${ }^{2}$ Médico Legista.

Cuerpo Médico Forense. Poder Judicial de Salta.

${ }^{3}$ Técnico Eviscerador. Cuerpo Médico Forense. Poder Judicial de Salta.

Correspondencia: Claudia Marcela Portelli Av. Bolivia 4671- PB Edificio Anexo Ministerio Público de Salta Ciudad de Salta. Argentina CP 4400. E-mail:marcela_portelli@ hotmail.com

Fecha de recepción: 12.NOV.2012

Fecha de aceptación: 12.DIC.2012 
Ataca al ganado solamente cuando su hábitat ha sido convertido en pastizales y sus presas naturales han disminuido ${ }^{3,4}$.

Se presenta un caso fatal de ataque de $P$. concolor a humano reportado en nuestra provincia.

\section{Presentación del caso}

Se practicó autopsia a una mujer de 23 años, con buen desarrollo óseo y muscular, pastora de rebaño caprino, quien fue encontrada sin vida después de ser atacada por un felino salvaje en la zona de la prePuna salteña, en la Finca El Alfarcito, situada a la entrada del Cerro Negro, departamento Rosario de Lerma en la Provincia de Salta, al Noroeste de la República Argentina (Figura 1).

Al examen externo presentaba las siguientes lesiones traumáticas.

Tres excoriaciones en región maxilar y submaxilar inferior izquierda, inmediatamente por debajo de éstas, en región anterior y lateral izquierda del cuello, presentaba tres heridas cortantes, de bordes irregulares con retracción e infiltración hemática, separadas una de otra por puentes cutáneos, las mismas medían $4 \times 2 \mathrm{~cm}, 3,5 \times 1,5 \mathrm{~cm}$ y $2,5 \times 1 \mathrm{~cm}$ respectivamente, compatibles con lesiones por garras de felino (Figura 2).

En región clavicular izquierda presentaba excoriaciones pequeñas sobre equimosis.

En la región posterior del cuello, en su parte media, herida de bordes irregulares, retraídos e infiltrados, de $3 \mathrm{~cm}$ de longitud que interesa piel, tejido celular subcutáneo y músculos angular y escaleno; con un trayecto descendente de arriba hacia abajo (Figura 3).

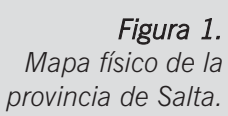

Figura 1. Mapa físico de la provincia de Salta.

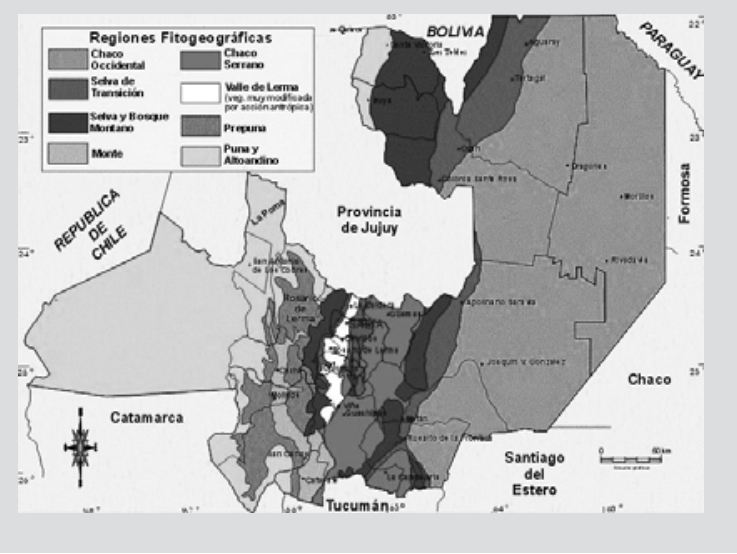

Presentaba herida de bordes irregulares en dedo pulgar de mano izquierda a la altura del pliegue entre la articulación de la $1^{\mathrm{a}}$ con la $2^{\mathrm{a}}$ falange.

En el examen interno se observó que las lesiones descritas en región anterior y lateral izquierda del cuello comprometían el tejido celular subcutáneo, aponeurosis superficial y profunda de cuello, músculos esternocleidomastoideo, esternocleidohioideo y esternohioideo, de aspecto desgarrado (Figuras 4 y 5 ).

Compromiso de vasos superficiales y profundos, con sección completa de la vena yugular interna izquierda; provocando una hemorragia aguda vital, la cual fue la causa del deceso (Figura 6).

\section{Discusión}

Las lesiones que se han descrito por el ataque de grandes felinos pueden ser una combinación de heridas contuso-cortantes, penetrantes, desgarros, caídas, aplastamiento y/o estallido, estos últimos se-

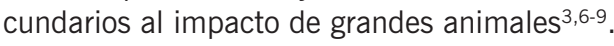

Generalmente cuando el animal ataca, lo hace sorpresivamente, no busca la cara, prefiere saltar por la espalda, en ocasiones sofocando a la presa, y encajando sus dientes entre la primera y segunda vértebra cervical, produciendo de esta forma lesiones tales como fracturas vertebrales, lo que resulta en laceración de médula espinal y lesión de los vasos principales del cuello, de esta forma se asegura la inmovilización de su presa3,6-10.

Estas características fueron comunes en los casos fatales revisados en la bibliografía, donde se observó que las lesiones predominantemente fueron desgarros de los tejidos blandos del cuerpo, concentrándose en región cervical, con sección de paquete vascular cervical, trauma de médula espinal y fracturas cervicales. Estas dos últimas lesiones no se observaron en el caso presentado, pero se consideró que el mecanismo de inmovilización de la presa fue similar ${ }^{1,3,7}$.

Algunos reportes describen evisceraciones de la víctima, esto no se observó en el caso planteado. Probablemente esto se deba a que el animal huyó ante la presencia de su principal enemigo y rival, el perro, quien es un compañero habitual en la labor de pastoreo $0^{1,3,7-9}$.

Cuando se llegó al lugar del hecho, no fue posible el avistaje del animal, pero considerando la fauna autóctona, y los reportes de los habitantes de la zona, creemos que el ataque fue perpetrado por un $P$. concolor. 
Los estigmas dejados en el cuello son de un tamaño superior al que podría producir el ataque del gato andino (O. jacobita), el cual muestra un comportamiento tranquilo, y no se siente perturbado por la presencia del humano, además, su altura no excede los $35 \mathrm{~cm}$. Lo que hace que su alimentación sea principalmente de roedores, aves, reptiles, etc., y no de grandes animales ${ }^{4,5,11}$.

El otro mamífero a considerar es el zorro colorado ( $P$. culpaeus), que si bien es carnívoro, prefiere no correr riesgos con presas de igual o mayor tamaño que él; razón por la cual se alimenta de roedores, reptiles, etc. Su hábito de alimentarse de carroña le ha creado la fama de asesino, ya que muchas veces se lo encuentran al lado del cadáver, por lo cual se mal presupone que fue el autor ${ }^{4,5,11}$.

Se descartó como autor al jaguar (Panthera onca) ya que no es su hábitat natural la zona árida de la Puna. Este felino se encuentra en la zona de yungas, bosques húmedos de la Región Chaqueña, al este de la provincia $^{5-11}$

EI $P$. concolor es un cazador solitario, el reconocimiento de su presa es importante y en general no reconocen a los seres humanos como víctimas, por el contrario, sigue al humano por curiosidad y escapa si se lo enfrenta ${ }^{1,2,4,10}$

Estos ataques se producen cuando el felino habita próximo a los humanos y generalmente suceden porque el humano invade su territorio, ya sea con fines recreativos, turísticos y/o para cazar, como así también por el crecimiento y expansión poblacional ${ }^{1,2,10}$.

En EE.UU. y Canadá desde 1890 a 2004 sólo se han registrado 88 ataques confirmados a humanos; de los cuales 20 fueron fatales ${ }^{1,12}$.

En Salta, si bien este tipo de animales salvajes pertenecen a la fauna autóctona, no existían hasta la fecha casos reportados de ataques fatales a humanos.

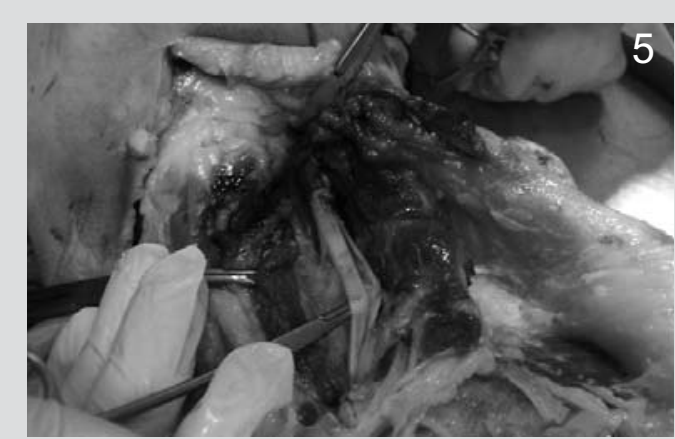

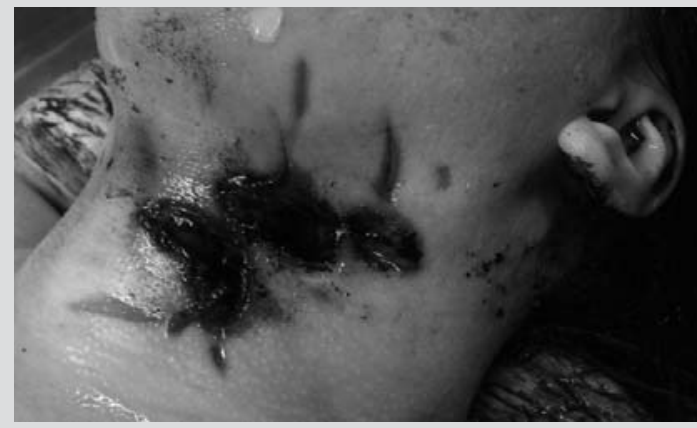

Figura 2.

Herida vital, compatible con garras de felino.

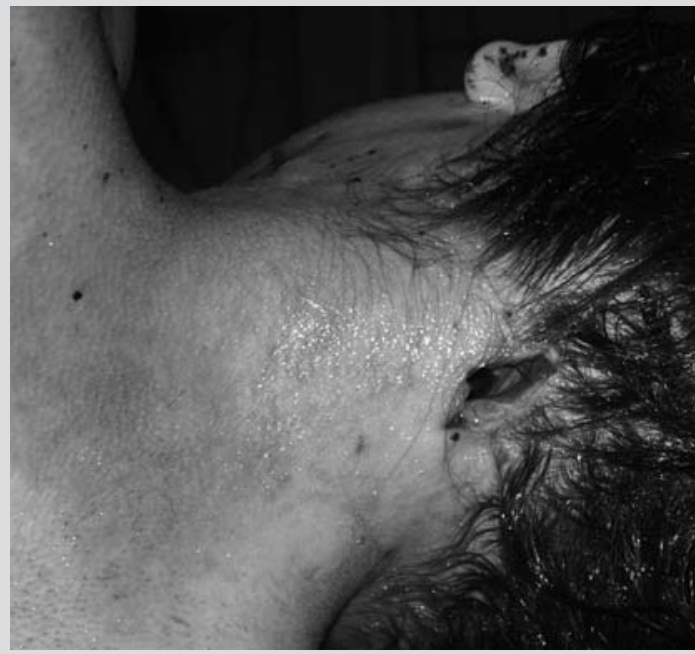

Figura 3.

Herida contuso-cortante en región posterior del cuello.

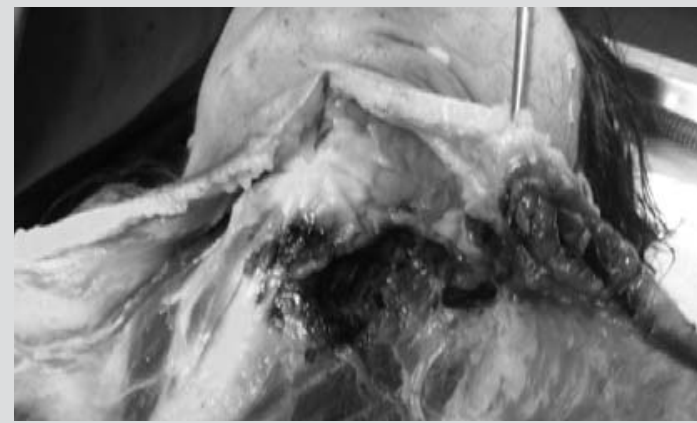

Figura 4.

Examen interno de cara anterior de cuello.

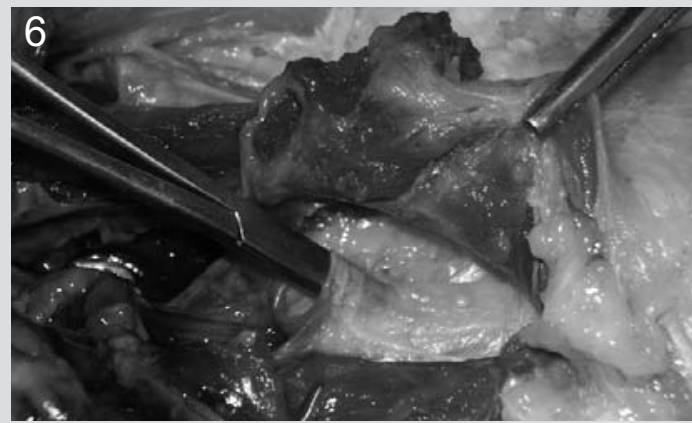

Figura 5.

Disección del paquete vascular izquierdo profundo del cuello.

Figura 6.

Vena yugular interna izquierda seccionada. 
Analizando la revisión bibliográfica, se observa que los reportes no son un número elevado, y en Argentina es el primero publicado ya que en el caso registrado en la provincia de Córdoba, se concluyó que las características de las lesiones se vinculaban más a ataque por una manada de perros, que al ataque por puma ${ }^{9}$, por lo que los autores consideran que éste trabajo será de gran aporte para las ciencias forenses.

\section{Bibliografía}

1. Campos Neto M, Garrone Neto D, Haddad V. Attacks by jaguars on Humans in central Brazil: Report of three cases, with observation of a death. Wilderness and Environmental Medicine 2011;22:130-5.

2. Mc Kee D. Cougat Attacks on humans: a Case report. Wilderness and Environmental Medicine 2003;14:169-73.

3. Chapenoire S, Camiade B, Legros M. Basic Instinct in a feline. J Forensic Sci. 2010;55:832-4.

4. Emmons L, Feer F. Mamíferos de los Bosques húmedos de América Tropical. Una Guía de Campo. Carnívoros (1º Ed). Editorial F.A.N 1999; pp. 169-71.

5. Jayat JP, Barquez R, Díaz M, et al. Aportes al conocimiento de la distribución de los carnívoros del noroeste de Argentina. Mastozoología Neotropical 1999;6(1):15-30.

\section{Agradecimiento}

Licenciada en Ciencias Biológicas Jimena Gato, por su aporte en la interpretación de las características de las diferentes especies carnívoras citadas.

6. Wiens M, Harrison P. Big Cat Attack: A case Study. The Journal of Trauma 1996;40:829-31.

7. Nabi D, Tak S, Halawai K. Injuries from leopard attacks in Kashmir. Int. J. Care Injuried. 2009;40:90-2.

8. Chum M, Ng WP. Traumatic tiger attack. J Neurosurg Pediatr. 2011;8:530-4.

9. Fonseca GM, Palacios R. An Unusual Case of Predation: Dog Pack or Cougar Attack? J Forensic Sci. 2012 Sep doi: 10.1111/j.1556-4029.2012. 02281.x.

10. Shaw HG, Beier P, Culver M, Grigione M. Puma Field Guide. The Cougar Network Disponible en www.cougarnet.org/Assets/pumafieldguide.pdf

11. Chan JM, Echevarria AL. Animales comunes de los bosques de Yungas. Mamíferos 1. 2005 disponible en: www.panamericanenergy.com/gx/pdf/mamiferos1.pdf.

12. Arizona game and fish department. Confirmed mountain lion attacks in the United States and Canada 1890 disponible en: www.azgfd.gov. 